\title{
Reconstruction of acetabular defects greater than Paprosky type 3B: the importance of functional imaging
}

Anna Di Laura ${ }^{1,2,3^{*}}$ (D), Johann Henckel ${ }^{1,2}$, Elisabetta Dal Gal ${ }^{2}$, Mohammed Monem', Maria Moralidou ${ }^{2}$ and Alister J. Hart ${ }^{1,2}$

\begin{abstract}
Background: 3D Surgical planning has become a key tool in complex hip revision surgery. The restoration of centre of rotation (CoR) of the hips and leg length $(\mathrm{LL})$ are key factors in achieving good clinical outcome. Pelvic imaging is the gold standard for planning and assessment of LL. We aimed to better understand if 3D planning is effective at equalising $\mathrm{LL}$ when large acetabular defects are present.
\end{abstract}

Materials and methods: This was a prospective case study of 25 patients. We report the analysis of pre-operative $L L$ status and planned LL restoration measured on $C T$, in relation to the achieved LL measured post-operatively in functional, weight bearing position. Our primary objective was the assessment of restoration of CoR as well as the anatomical and functional LL using biplanar full-length standing low-dose radiographs; our secondary objective was to evaluate the clinical outcome.

Results: Pre-operative intra-pelvic discrepancy between right and left leg was a mean of $28 \mathrm{~mm}$ (SD 17.99, $\mathrm{min}=3$, $\max =60 \mathrm{~mm}$ ). Post-operatively, the difference between right and left vertical femoral offset (VFO), or CoR discrepancy, was of $7.4 \mathrm{~mm}$ on average, significantly different from the functional LL discrepancy (median $=15 \mathrm{~mm}$ ), $p=0.0024$. Anatomical LLD was a median of $15 \mathrm{~mm}$. In one case there was transient foot drop, one dislocation occurred 6 months post-operatively and was treated by closed reduction, none of the patients had had revision surgery at the time of writing. Mean oxford hip score at latest follow up was 32.1/48.

Discussion: This is the first study to investigate limb length discrepancy in functional position after reconstruction of large acetabular defects. We observed that VFO is not an optimal surrogate for LL when there is significant bone loss leading to length inequality, fixed flexion of the knee and abduction deformity.

Conclusions: Although challenging, LLD and gait abnormalities can be greatly improved with the aid of an accurate surgical planning. Surgeons and engineers should consider the integration of EOS imaging in surgical planning of reconstruction of large acetabular defects.

\footnotetext{
* Correspondence: anna.laura.14@ucl.ac.uk

${ }^{1}$ The Royal National Orthopaedic Hospital, Brockley Hill, Stanmore, London HA7 4LP, UK

${ }^{2}$ Institute of Orthopaedics and Musculoskeletal Science, University College London, London, UK

Full list of author information is available at the end of the article
}

C The Author(s). 2021 Open Access This article is licensed under a Creative Commons Attribution 4.0 International License, which permits use, sharing, adaptation, distribution and reproduction in any medium or format, as long as you give appropriate credit to the original author(s) and the source, provide a link to the Creative Commons licence, and indicate if changes were made. The images or other third party material in this article are included in the article's Creative Commons licence, unless indicated otherwise in a credit line to the material. If material is not included in the article's Creative Commons licence and your intended use is not permitted by statutory regulation or exceeds the permitted use, you will need to obtain permission directly from the copyright holder. To view a copy of this licence, visit http://creativecommons.org/licenses/by/4.0/. The Creative Commons Public Domain Dedication waiver (http://creativecommons.org/publicdomain/zero/1.0/) applies to the data made available in this article, unless otherwise stated in a credit line to the data. 


\section{Introduction}

Managing large acetabular defects remains a challenging task in revision total hip arthroplasty (THA) [1-4], usually correlated with mechanical deficiency [2]. Goals include reconstructing bone morphology and optimal positioning of the acetabular component to restore centre of rotation (COR) and leg lengths (LL) [5].

Leg length discrepancy (LLD) is associated with a number of pathologies including gait and posture abnormalities [6-8] arthritis of lower limbs and lumbar spine [7] as well as sciatic nerve damage [9]. Although a number of studies have reported on LL restoration following primary THAs [10-14], LL following complex acetabular reconstruction has not been largely addressed.

In case of significant bone loss, CT-based planning is essential to restore the CoR [15]. In planning revision surgery, the patients are CT scanned in supine position [16]; due to the limited field of view, vertical femoral offset (VFO) is used as a surrogate measure for LL. This eliminates key information with regards to functional LL. Low-dose biplanar radiography (LDBR) offers the possibility of upright full length imaging and 3D reconstruction of the limbs to accurately measure LL [17].

We aimed to better understand if CT planning is effective at equalising the limbs when large acetabular defects are present. Our primary objective was to measure the achieved differences in right and left CoR (difference in VFO) as well as functional and anatomical LLD from post-operative standing EOS imaging. Our secondary objective was to evaluate clinical outcomes including OHS, walking status, dislocation rate, revision rate, nerve injury.

\section{Materials and methods}

\section{Study design and outcome measures}

Twenty-five patients with large acetabular defects were a candidate for receiving a custom 3D printed acetabular cup. All cases had radiographic evidence (confirmed on CT and plain radiograph) of at least a Paprosky type 3B acetabular defect, including discontinuities.

The patients were post-operatively evaluated using standing 3-dimensional (3D) imaging system (EOS; EOS Imaging SA, Paris, France) at the time of manuscript writing and were therefore included in the study. We report the analysis of pre-operative LLD status and planned CoR restoration in relation to the achieved LL measured post-operatively in functional, weight bearing position, Fig. 1.

There were 16 females and 9 males; mean age at surgery was 67 years (range 49-90).

Patient demographics are displayed in Table 1.

Component design and pre-operative planning were undertaken with close collaboration between surgeons and engineers. Continued follow up (median 37 months,

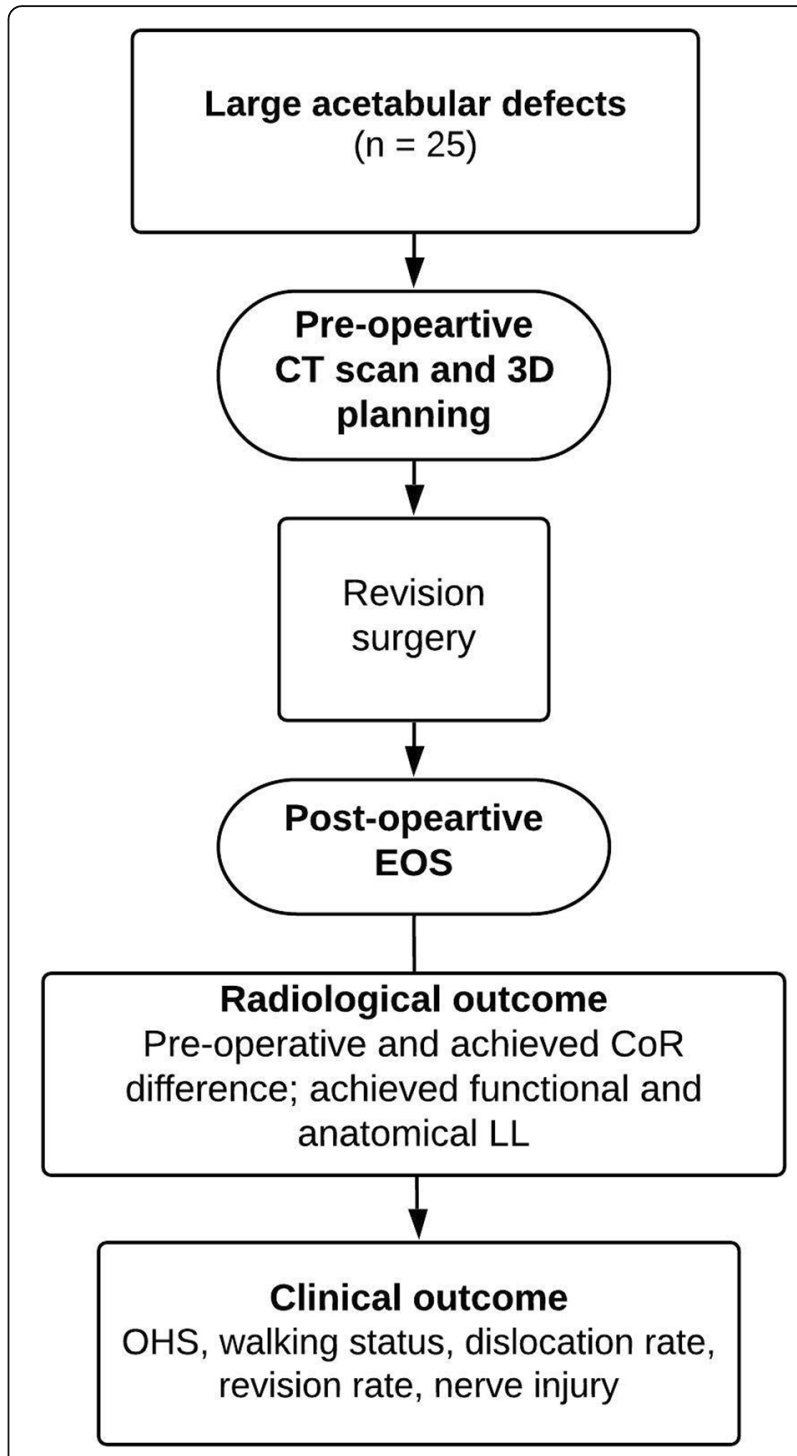

Fig. 1 Flowchart of the study design

range 20-52) was performed to monitor clinical outcome.

The outcome measures were: 1) Pre-op Vs achieved VFO, 2) Post-operative anatomical and functional LL 3) OHS, walking status, dislocation rate, revision rate, nerve injury.

\section{Pre-operative planning}

The patients underwent metal artefact reduction sequencing CT scanning of their whole pelvis. All patients were imaged with a Siemens SOMATOM ${ }^{\circ}$ Definition AS+ 128 slice CT scanner. Images were acquired at $100 \mathrm{kV}, 100$ mAs [21]. Data was saved as DICOM files, anonymised and provided to the manufacturer, via a secure dedicated portal, to be included into a specific workflow for implant design. 
Table 1 Patients' characteristics

\begin{tabular}{|c|c|c|c|c|}
\hline Case & BMI & $\begin{array}{l}\text { Op } \\
\#^{\mathrm{a}}\end{array}$ & $\begin{array}{l}\text { Pre-operative } \\
\text { walking aids }\end{array}$ & Reason for revision \\
\hline 1 & 22 & 1 & Frame with wheels & Loose right total hip replacement with massive bony defects in the acetabulum \\
\hline 2 & 25 & 2 & $\begin{array}{l}\text { Walking stick and } \\
\text { crutches }\end{array}$ & Loosening of revision hip arthroplasty \\
\hline 3 & 32 & 2 & $\begin{array}{l}\text { Bilateral underarm } \\
\text { crutches }\end{array}$ & Pelvic discontinuity following revision left hip repl. \\
\hline 4 & 30 & 3 & Frame & $\begin{array}{l}\text { Dislocated revision right total hip with a constrained liner. Periprosthetic type } C \text { fracture, managed by open } \\
\text { reduction internal fixation with distal femoral locking plate }\end{array}$ \\
\hline 5 & 31 & 2 & 2 crutches & Massive acetabular defect and loose hip replacement. High CRP with negative aspirate \\
\hline 6 & 32 & 3 & Wheelchair & Failed MoM implant, subsequent loosening and infection of the THR \\
\hline 7 & 26 & Multi ${ }^{b}$ & 2 crutches & Multiple hip operations, severe mechanical symptoms \\
\hline 8 & 48 & 2 & Wheelchair & Failed replacement with acetabular migration \\
\hline 9 & 29 & 2 & None & Failure of MoP hip replacement with superior migration of the hip \\
\hline 10 & 23 & 2 & Wheelchair & Loose $\mathrm{R}$ hip replacement with inflammatory pseudotumor \\
\hline 11 & 37 & Multi $^{b}$ & Walking crutches & Loose left long stem, loose acetabulum \\
\hline 12 & 26 & 1 & Bilateral crutches & Loose $R$ acetabulum MoP replacement with subluxation \\
\hline 13 & 23 & 1 & None & MoM hip resurfacing with high metal ions levels and bone and soft tissue damage \\
\hline 14 & 27 & 2 & Bilateral crutches & Failed MoP L hip with superior migration of cup and stem, pelvic discontinuity \\
\hline 15 & 26 & 0 & Walking crutches & Severe joint degradation. Presence of massive fractured bone protrusion below acetabulum \\
\hline 16 & 26 & 2 & Wheelchair & Failed implant and infection \\
\hline 17 & 30 & 2 & Frame with wheels & Infection and pelvic discontinuity \\
\hline 18 & 22 & 1 & Bilateral crutches & Acetabular cup failure following primary R THA \\
\hline 19 & 26 & 0 & None & Hip Osteoarthritis secondary to acetabular fracture \\
\hline 20 & 23 & 2 & Walking trolley & Catastrophic failure of revision right hip replacement \\
\hline 21 & 30 & 4 & Wheelchair & Loosening and infection \\
\hline 22 & 27 & 1 & Walking stick & Loosening of acetabular component and significant osteolysis \\
\hline 23 & 22 & 1 & Walking stick & MoM modular hip replacement with pseudotumor \\
\hline 24 & 26 & Multi $^{b}$ & Frame & History of recurrent dislocation and infection \\
\hline 25 & 25 & Multi ${ }^{b}$ & Wheelchair & Multiple severe infections and metallosis from THA \\
\hline
\end{tabular}

a Op \#, total number of hip replacements including one in study. MoM, Metal on Metal; MoP, Metal on Polyethylene; R, Right; L, Left

${ }^{b}$ Multi, no data on total number of hip replacements available greater than 2 known.

Once approved, the customised implants were produced using electron beam melting EBM additive manufacturing with regions of trabecular titanium to promote osteointegration [18]. Intra-operatively, plastic models of the patient's anatomy, the bespoke implant and the drill guides were manufactured using 3D printing and sterilised for intraoperative use.

Data from CT scans was used for the accurate assessment of the centre of rotation of the failed hip. The difference in VFO between the right and left side was used as surrogate measure for LL on pelvic CT scans as the full leg is not imaged. These measurements informed on the pre-operative LL status.

LL from 3D CT reconstruction was considered the distance between left and right hip joint centre of rotation when the pelvis has a sagittal tilt of $0^{\circ}$ (the anterior pelvic plane corresponds to the coronal plane of the body), Fig. 2.
Designing the customised titanium implant involved filling the defect with porous titanium, assuring fixation with structural titanium and screw holes and determining the optimal location of centre of rotation so that to restore optimal biomechanics.

Equalization of left and right centre of rotation was not always the goal. Decision was made on a case-basis considering the bone stock and anatomical characteristics, Fig. 3.

\section{Surgical procedure}

Surgical procedures were conducted by one senior orthopaedic surgeon who was sometimes accompanied by another senior orthopaedic surgeon and/or senior vascular surgeon. The key steps in surgery were: an extensive posterior approach, reaming of non-viable bone as per plan, trial with $3 \mathrm{D}$ printed plastic implant model and fixation of 3D printed titanium implant with screws 

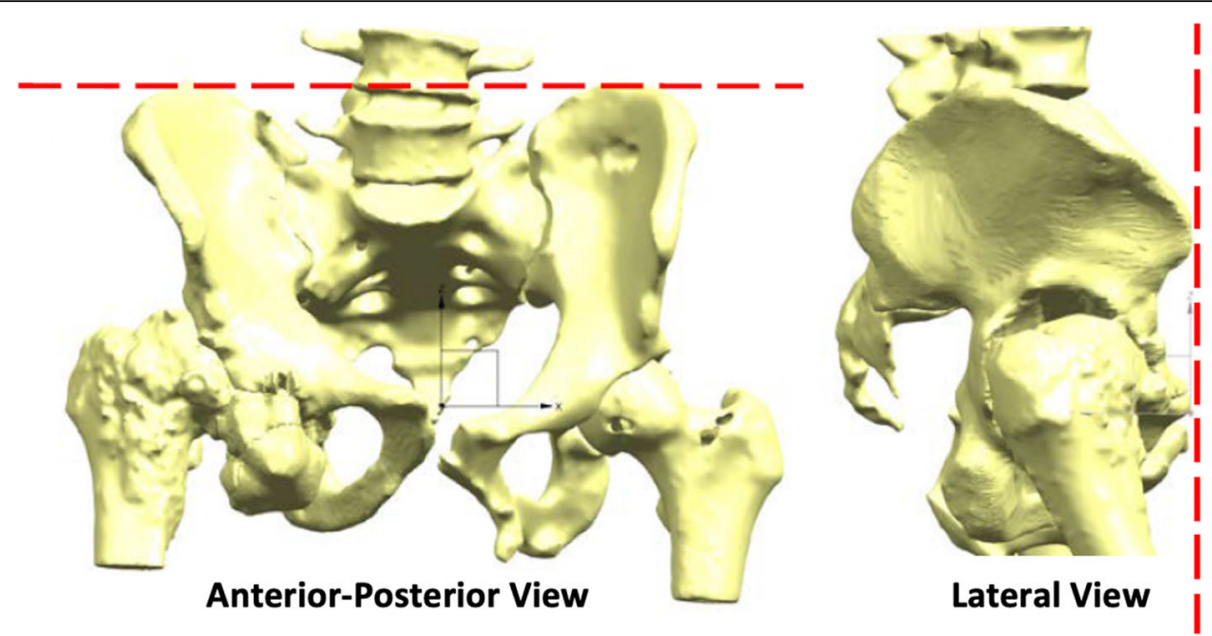

Fig. 2 Anteroposterior and lateral views of CT-reconstructed anatomy oriented with $0^{\circ}$ pelvic tilt and rotation. The AnteroSuperior Iliac Spines (ASIS) and the pubic symphysis (PS) lie on the same plane

and patient specific drill guides. 3D printed patient anatomy helped with appreciating the size of the defect, assisting with surgical exposure, guiding surgical orientation, preparing the bone.

\section{Post-operative radiological and clinical outcome}

EOS scans were taken post-operatively. The simultaneous biplanar acquisition was used to perform stereoradiographic 3D modelling of each lower extremity using specialized software (sterEOS 3D; EOS Imaging SA) [19]. Bilateral VFO as well as full leg segments were measured on EOS scan post-operatively.

VFO was measured as the vertical distance between the joint CoR and the inter-ischial tuberosity line [20, 21]. The difference between right and left VFO was used to measure LLD, as conventionally done when full limb length scans are not available.

Moreover, full length measurements of leg length were also taken, the following definitions were used. Anatomical femoral length: distance between the centre of the femoral head (native or implant) and the centre of the trochlea. Anatomical tibial length: distance between the centre of the tibial spine and the centre of the tibial plafond. Functional leg length: distance between the centre of the femoral head (native or implant) to the centre of the ankle joint. Anatomical length: sum of the anatomical femoral and tibial lengths, Fig. 4.

VFO and LL measurements were performed separately by two examiners to test reproducibility.

Follow-up of patients was performed by the senior authors to monitor for complications. Post-operative

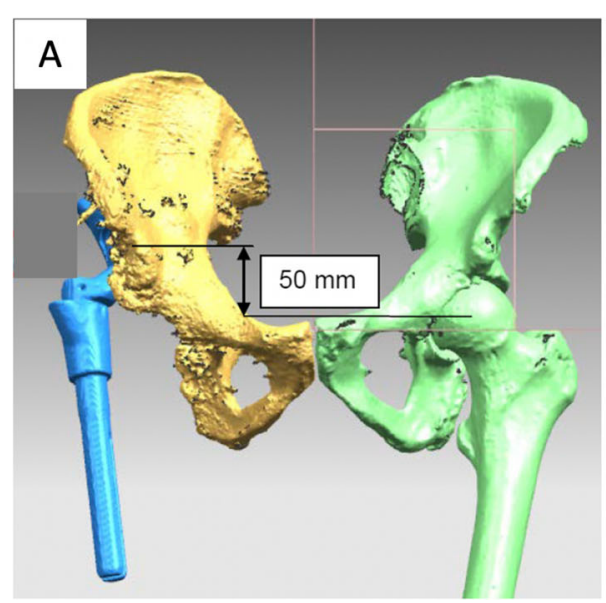

B

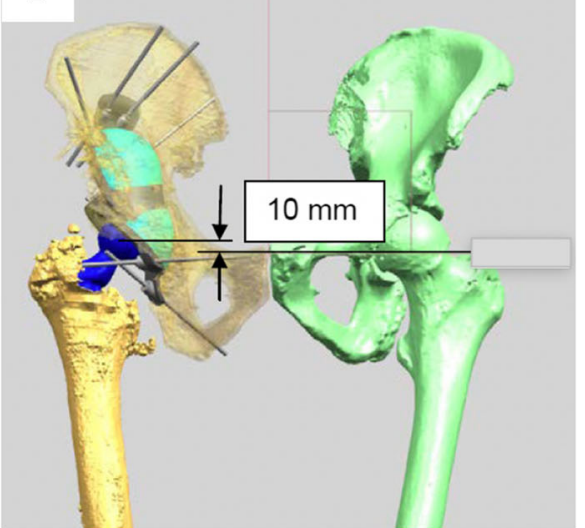

Fig. 3 Example of CT surgical plan where complete equalization of left and right centre of rotation was not the goal, a residual $10 \mathrm{~mm}$ difference between right and left hip was planned. Decision was made considering the anatomical characteristics of the patients alongside with the design of the bespoke implant to be inserted in the acetabular cavity 


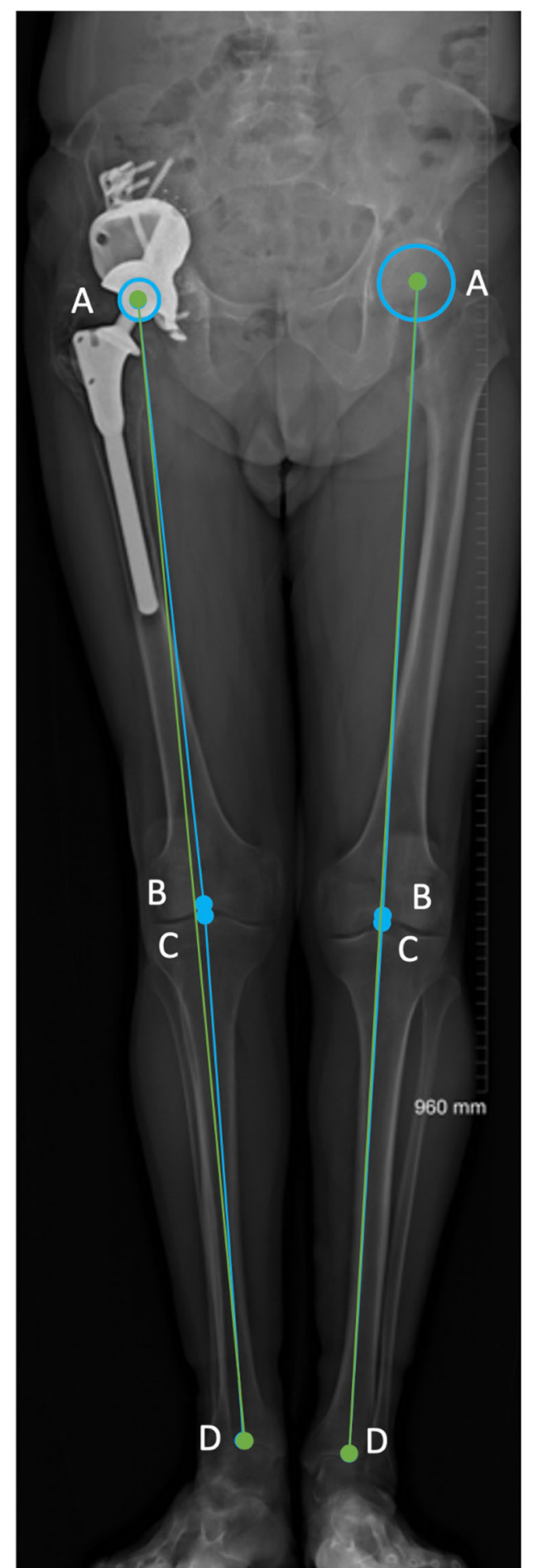

Fig. 4 Anatomic vs functional length. (1) Anatomical femoral length: distance between the centre of the femoral head (a) and the centre of the trochlea (b). (2) Anatomical tibial length: distance between the centre of the tibial spine (intercondylar eminence) (c) and the centre of the ankle joint (d). (3) Functional length: distance between the centre of the femoral head to the centre of the ankle joint (AD). (4) Anatomical length: sum of the anatomical femoral and tibial lengths $(A B+C D)$ walking status and oxford hip scores [22] were recorded during latest follow up ( 20 to 52 months, median 37 months).

\section{Statistical analysis}

Statistical analyses were performed using SPSS ${ }^{\bullet}$ Statistics Version 24 (IBM Corp., Armonk, NY, USA). Intraclass correlation coefficient (ICC) tested the reproducibility of the method of analysis performed by the two examiners. We considered an ICC of $>0.90$ as high, between 0.80 and 0.90 as moderate, and $<0.80$ as insufficient. Normal distribution of the values was checked by means of the D'Agostino-Pearson omnibus normality test for each series of measurements. For data with normal distribution, paired Student's t-test was used for analysis. For data without normal distribution, related samples Wilcoxon signed rank test was used for the analysis. The significance level was set at $5 \%$.

\section{Results}

Radiological assessment: pre-operatively

The pre-operative VFO discrepancy between right and left leg was a mean of $28 \mathrm{~mm}$ (SD 17.99, $\min =3, \max =$ $60 \mathrm{~mm}$ ). The surgical plan predicted a pelvic discrepancy between right and left leg (residual difference) of 3.08 $\mathrm{mm}$ on average $(\mathrm{SD} 6.9, \min =0, \max =27 \mathrm{~mm})$, Fig. 5 .

\section{Radiological assessment: post-operatively}

Post-operatively, the VFO discrepancy between right and left leg was a mean of $7.4 \mathrm{~mm}(\mathrm{SD} 5.7, \min =0, \max =$ 23),

Functional LLD was a median $15 \mathrm{~mm}$ (IQR, $6 \mathrm{~mm}$, $23.50 \mathrm{~mm}$; $\min =0, \max =62$ ). Anatomical LLD was a median of $15 \mathrm{~mm}(\mathrm{IQR}, 4.5 \mathrm{~mm}, 22 \mathrm{~mm}$; $\min =0$, $\max =$ 63); Fig. 6. The difference was not statistically significant $(p=0.17)$.

The difference between VFO discrepancy and functional LLD was found to be statistically significant, $p=$ 0.0024 Fig. 7.

Nine cases (36\%) showed a difference larger than 10 $\mathrm{mm}$ between VFO discrepancy and functional LLD. Length inequality, fixed flexion of the knee as well as and abduction deformity were present singularly of combined in these cases, Fig. 8.

\section{Reproducibility}

Intraclass correlation coefficient ICC showed excellent reproducibility between the two examiners for the measurement of post-operative $\mathrm{CoR}(\mathrm{ICC}=0.96,95 \% \mathrm{CI}, 0.90$ to $0.98, p<0.0001$ ); for functional LL (ICC $=0.99,95 \%$ CI, 0.997 to $0.994, p<0.0001$ ); and anatomical LL (ICC = $0.93,95 \% \mathrm{CI}, 0.83$ to $0.97, p<0.0001$ ); 


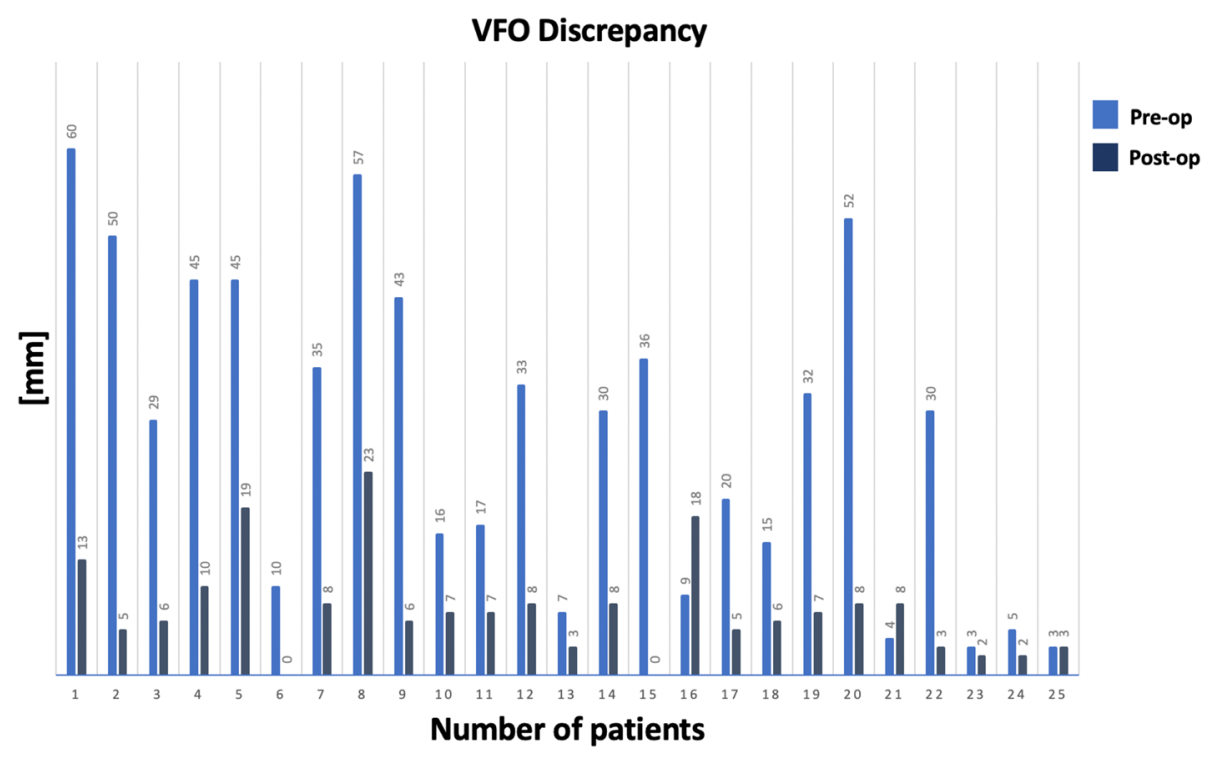

Fig. 5 Column chart showing VOF discrepancy in all patients pre and post-operatively

\section{Clinical outcome}

Duration of post-operative follow up and post-operative walking status are shown in Table 2. Mean oxford hip score at latest follow up was 32.1/48.

\section{Discussion}

In recent years, image analysis and 3D printing technology, in particular the use of patient-matched 3D printed cups, have allowed patients to walk again. LL equality is an important goal of any hip arthroplasty procedure as it affects functional outcome, and it is particularly challenging in revision surgery in presence of major complex lower limb deformity. Imaging of the pelvis and femurs is the gold standard used pre and post-operatively for planning and assessing limb length.

In planning revision surgery to design customised implants, the patients are CT scanned in supine position [16] and the true functional LL cannot be evaluated.

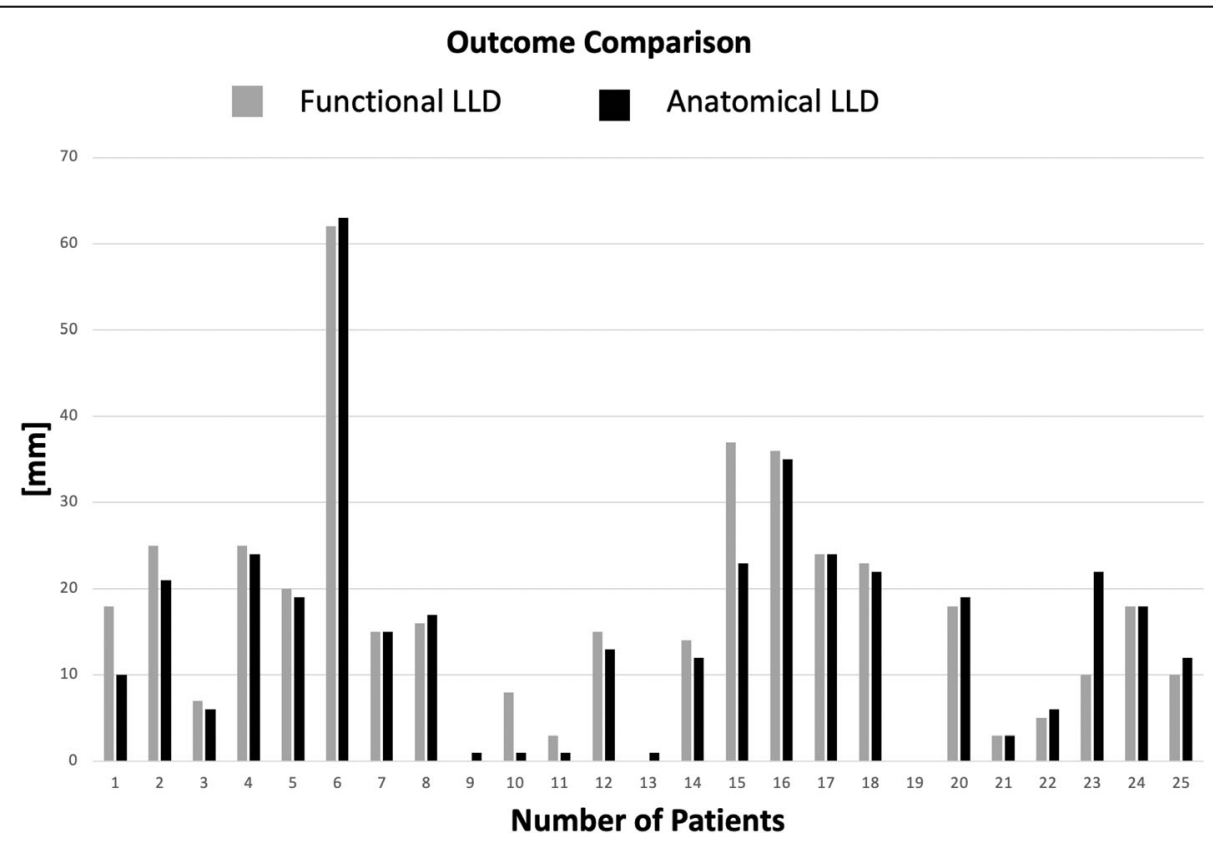

Fig. 6 Column chart showing the functional LLD Vis-à-vis with the anatomical LLD for each case 


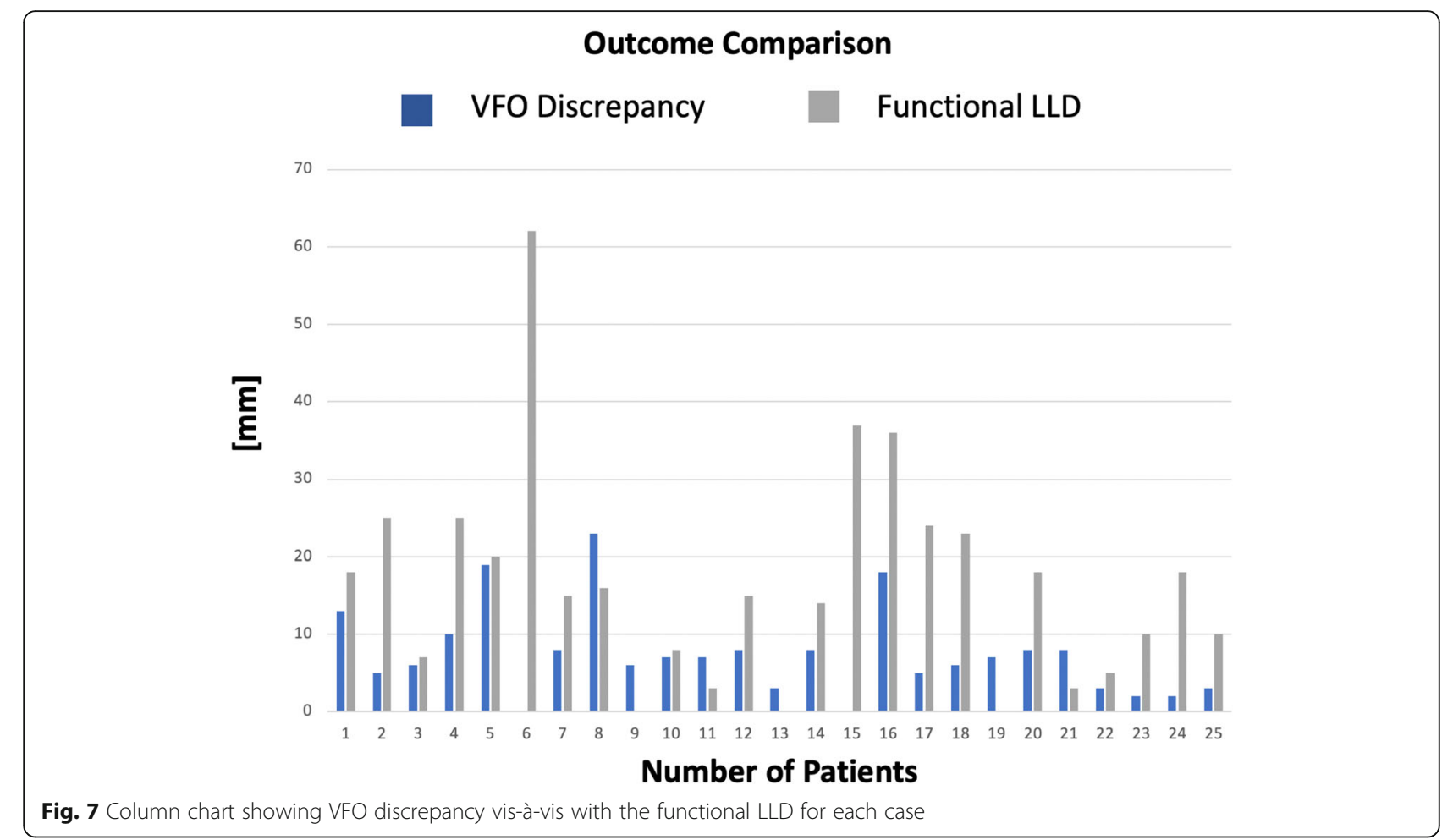

Pelvic measurements of VFO constitute a surrogate for LL [23], but that can lead to significant limitations not taking into account any causes of LLD which do not involve the hip [24]; including abnormal pelvic orientation, bone length inequality, fixed flexion and asymmetrical femoral and tibial torsion [25]. LDBR, EOS, offers upright imaging and $3 \mathrm{D}$ reconstruction of the lower limbs to accurately measure LL with low radiation exposure and with negligible magnification errors [17].

We aimed to understand if 3D planning is effective at equalising the limbs when large acetabular defects are present, to measure the amount of CoR that can be

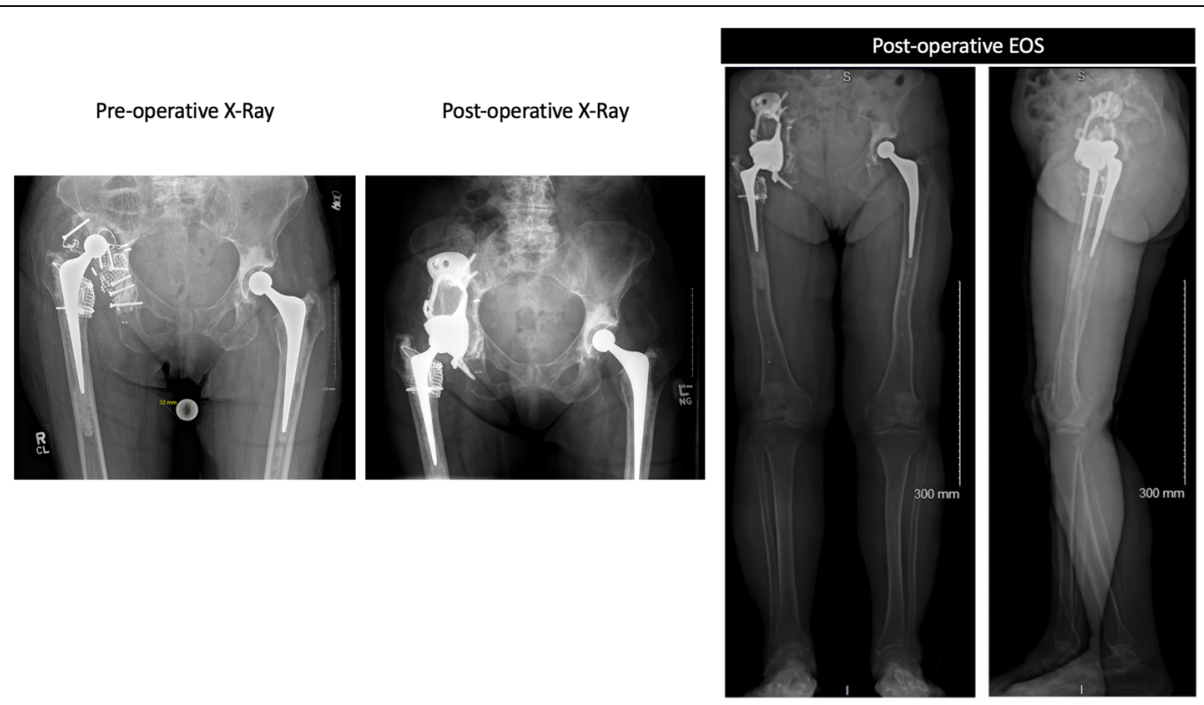

Fig. 8 Case example. Pre-operative AP X-Ray (left image) showing major migration of the right hip, discrepancy between right and left VFO was $5 \mathrm{~cm}$. Post-operative pelvic AP X-Ray (middle images) shows good restoration of centre of rotation, VFO discrepancy was $8 \mathrm{~mm}$. Functional LLD measured on post-opeartive EOS imaging (right image) was $18 \mathrm{~mm}$. Knee flexion can be observed on the lateral EOS image (left knee flexion = $18^{\circ}$, right flexion $=3^{\circ}$, difference in femur length $=2.5 \mathrm{~cm}$ 
Table 2 Post-operative outcomes

\begin{tabular}{|c|c|c|c|}
\hline Case & Follow-up time (months) & Post-operative walking aids & Complications \\
\hline 1 & 52 & Unilateral walking stick & Nil \\
\hline 2 & 50 & None & Transient foot drop \\
\hline 3 & 47 & Unilateral walking stick & Nil \\
\hline 4 & 45 & Unilateral crutch & Nil \\
\hline 5 & 48 & None & Nil \\
\hline 6 & 45 & Bilateral crutches, electric chair outside & Nil \\
\hline 7 & 45 & Unilateral walking stick & Nil \\
\hline 8 & 35 & Bilateral elbow crutches & Nil \\
\hline 9 & 37 & None & Nil \\
\hline 10 & 38 & None & Nil \\
\hline 11 & 34 & Bilateral crutches & Nil \\
\hline 12 & 35 & Bilateral crutches & Nil \\
\hline 13 & 29 & Bilateral crutches & Nil \\
\hline 14 & 42 & Unilateral walking stick & Nil \\
\hline 15 & 39 & Walking crutches & Nil \\
\hline 16 & 22 & Zimmer frame & Dislocation \\
\hline 17 & 29 & Zimmer frame & Nil \\
\hline 18 & 25 & Unilateral walking stick & Nil \\
\hline 19 & 24 & None & Nil \\
\hline 20 & 26 & Unilateral walking stick & Nil \\
\hline 21 & 24 & Bilateral crutches & Nil \\
\hline 22 & 24 & None & Nil \\
\hline 23 & 20 & One crutch outdoors & Nil \\
\hline 24 & 26 & Bilateral crutches & Nil \\
\hline 25 & 25 & Bilateral crutches & Nil \\
\hline
\end{tabular}

brought down without compromising nerve functionality, in other words, if VFO is a good surrogate for LL in acetabular reconstruction.

We reported on the measurement of functional LL following reconstruction of significant acetabular defects. We found that post-operatively, the CoR discrepancy between right and left leg was of $7.4 \mathrm{~mm}$ on average (SD $5.7, \min =0, \max =23$ ), therefore within the "safe" range of discrepancy [25-27]. There was a significant difference between the difference in right and left VFO and the measure of functional LLD. 36\% of the cases $(9 / 25)$ presented a difference larger than $10 \mathrm{~mm}$ between VFO discrepancy and functional LLD. Length inequality, fixed flexion of the knee as well as and abduction deformity were present singularly of combined in these cases.

No revision surgery has occurred to date, one patient dislocated the hip 6 months post-operatively. It was treated with one close reduction procedure with no further dislocation. One patient presented with a transient foot drop post-operatively which resolved over time. Mean oxford hip score at latest follow up was 32.1/48.
Incidence, extent and impact of LLD after THA

LLD is defined as the inequality in the overall length of the right and left lower limb, it occurs in up to $70 \%$ of the entire population [28]. As many as one-third of healthy asymptomatic individuals have $5 \mathrm{~mm}$ to $2 \mathrm{~cm}$ of limblength discrepancy and may not be aware of it. In fact, there are multiple potential compensatory mechanisms, such as toe-walking on the shorter side, circumduction and knee flexion of the longer side, or hyperpronation [25]. These compensatory mechanisms often act simultaneously to aid gait and may be present in patients with large acetabular defects before revision surgery.

LLD is classified as clinically relevant when it exceeds $20 \mathrm{~mm}$ [26]. Failure of hip implants, congenital conditions, tumour, trauma can lead to LL disparity and significant CoR displacement, often exceeding the level beyond which the risk of neurological damage is possible. LLD is associated with gait and posture abnormalities [6-8] and numerous clinically relevant issues, including arthritis of lower limbs and lumbar spine [7] as well as sciatic nerve damage [9]. 
It is unclear the extent of LL that can be safely restored after revision arthroplasty in patients with large acetabular defects. Complete equality between leg lengths is considered ambitious, a discrepancy of up to $10 \mathrm{~mm}$ has been generally set as an acceptable threshold in literature. However, this is not based on studies including severe acetabular bone loss.

For these cases, literature has reported LLD ranging from 3 to $70 \mathrm{~mm}$, with an incidence of 1 to $17 \%$ after primary hip replacement [29] and 1 to $50 \%$ after total hip replacement in general [30]. The range of the average LLD reported after primary surgery, is between 3 and $17 \mathrm{~mm}$; the range is 20 to $40 \mathrm{~mm}$ in case of large bony defects. Generally, a leg lengthening of more than $10 \mathrm{~mm}$, is often observed after THA in half cases [29]. A clear distinction between acceptable and unacceptable LLD is yet to be defined.

LLD is negatively correlated with a high Oxford Hip Score (OHS), normal gait, body posture and patients perceiving LLD often complain for lower back pain, as well as, general dissatisfaction and they are commonly in need of shoe elevation [29]. These may lead to early dislocation or loosening, resulting in surgical failure and recurrence of surgery [30]. Clinically relevant issues, such as arthritis and sciatic nerve injury, have been also associated with leg discrepancies. Nerve palsy is correlated with the amount of lengthening performed during surgery, but there is no known safe threshold [25].

\section{Measuring LLD}

Methods of correcting LLD include 2D or 3D preoperative planning using X-Rays or CTs, intraoperative identification of anatomical landmarks and navigation techniques [24]. Computer-assisted navigation techniques rely on the usage of intraoperative landmarks. This method generally eliminates errors, but is considered an unwieldy and expensive tool, beside the steep learning curve. Pre-operative planning (2D) based on radiographs remains the gold standard, although of 2D nature and associated with magnification issues and therefore unreliable. CT-based 3D planning overcomes this at the expense of higher radiation dose. For this reason, CT acquisition has a limited field of view, it usually excludes images of full lower limbs.

\section{Comparison with previous studies}

The range of pre-operative VFO discrepancy found in our study group aligns with what reported by Joshi et al. [31] documenting on the clinical outcome of using titanium cementless customised implants in patients with large acetabular deficiency. Mean pre-operative discrepancy was reported to be $35 \mathrm{~mm}$ (range $10-40 \mathrm{~mm}$ ) and post-operative LLD $15 \mathrm{~mm}$, with two patients having more than $20 \mathrm{~mm}$ discrepancy post-operatively. Garbuz et al. [5], who recorded the mid-term clinical outcome of allografts in patients with acetabular defects, reported a mean pre-operative LLD of $29 \mathrm{~mm}$ (range $10-60 \mathrm{~mm}$ ) and a post-op LLD of $8 \mathrm{~mm}$ (range 0 to $30 \mathrm{~mm}$ ), with 1 patient having more than $20 \mathrm{~mm}$ discrepancy. All measurements were performed on AP pelvic radiographs, thus with limited accuracy.

\section{Limitations}

We acknowledge limitations. Firstly, pre-operative EOS imaging was not available for all the presented patients and therefore it was not possible to verify pre-existing conditions below the hip joint. We therefore excluded the measurement of pelvic orientation which affects LL but it is known to potentially vary after surgery. Secondly, we did not investigate the degree of any foot deformities radiographically as this would have been challenging to assess with the available data. Lastly, we acknowledge the small sample size of these extremely difficult cases, although our hospital constitutes the largest orthopaedic hospital in the UK, highlighting the rarity of their kind.

\section{Conclusions}

This is the first study to investigate limb length discrepancy in functional position after reconstruction of large acetabular defects. VFO is not an optimal surrogate for LL when there is significant bone loss leading to length inequality, fixed flexion of the knee and abduction deformity.

Although challenging, LLD and gait abnormalities can be greatly improved with the aid of an accurate surgical planning. Surgeons and engineers should consider the integration of EOS imaging in surgical planning of reconstruction of large acetabular defects.

\section{Acknowledgments}

This research was funded by the Medical Research Council (MRC), The Maurice Hatter Foundation, the RNOH Charity, the Rosetrees Trust and the Stoneygate Trust, and supported by researchers at the National Institute for Health Research, University College London Hospitals Biomedical Research Centre.

\section{Authors' contributions \\ Study Design: $A H, J H$ and AD. Data collection: $A H, J H, M M o, E D, A D$. Data analysis: $A H, J H, E D, A D$. Literature search: ED, MMon, MMor, AD. Data interpretation: $A H, A D, J H$. Manuscript writing: $A H, A D, J H, E D, M M o n, M M o r$. The authors read and approved the final manuscript.}

\section{Funding}

This research did not receive any specific grant from funding agencies in the public, commercial, or not-for-profit sectors.

Availability of data and materials

The datasets used and/or analysed during the current study are available from the corresponding author on reasonable request. 


\section{Ethics approval and consent to participate}

We confirm that all investigations were conducted in conformity with ethical principles of research and that institutional approval was obtained (SE16.021). The patients have given written consent to participate.

\section{Consent for publication}

The patients have given written consent to publish.

\section{Competing interests}

The authors have no potential conflicts of interest to report.

\section{Author details}

${ }^{1}$ The Royal National Orthopaedic Hospital, Brockley Hill, Stanmore, London HA7 4LP, UK. ${ }^{2}$ Institute of Orthopaedics and Musculoskeletal Science, University College London, London, UK. ${ }^{3}$ Department of Mechanical Engineering, University College London, London, UK.

Received: 14 September 2020 Accepted: 10 February 2021 Published online: 20 February 2021

\section{References}

1. Cano JJ, Guillamet L, Pons AP. Reconstrução acetabular em defeitos por paprosky tipo III. Acta Ortopédica Brasileira. 2019;27(1):59-63.

2. Hansen $E$, Shearer D, Ries MD. Does a cemented cage improve revision THA for severe acetabular defects? Clin Orthop Relat Res ${ }^{\circledast}$. 2011:469(2):494-502.

3. Van Egmond N, De Kam DC, Gardeniers JW, Schreurs BW. Revisions of extensive acetabular defects with impaction grafting and a cement cup. Clin Orthop Relat Res. ${ }^{\oplus}$ 2011;469(2):562-73.

4. Buckup J, Salinas EA, Della Valle AG, Boettner F. Treatment of large acetabular defects: a surgical technique utilizing impaction grafting into a metallic mesh. HSS Journal ${ }^{\bullet} .2013 ; 9(3): 242-6$.

5. Garbuz D, Morsi E, Mohamed N, Gross AE. Classification and reconstruction in revision acetabular arthroplasty with bone stock deficiency. Clin Orthop Relat Res. ${ }^{\oplus}$ 1996;324:98-107.

6. Khamis S, Danino B, Ovadia D, Carmeli E. Correlation between gait asymmetry and leg length discrepancy — what is the role of clinical abnormalities? Appl Sci. 2018;8(10):1979.

7. Sabharwal S, Kumar A. Methods for assessing leg length discrepancy. Clin Orthop Relat Res. 2008;466(12):2910-22.

8. Renkawitz T, Weber T, Dullien S, Woerner M, Dendorfer $\mathrm{S}$, Grifka J, et al. Leg length and offset differences above $5 \mathrm{~mm}$ after total hip arthroplasty are associated with altered gait kinematics. Gait Posture. 2016;49:196-201.

9. Abdel MP, Trousdale RT, Berry DJ. Pelvic discontinuity associated with total hip arthroplasty: evaluation and management. JAAOS-J Am Acad Orthop Surgeons. 2017;25(5):330-8.

10. Williamson JA, Reckling FW. Limb length discrepancy and related problems following total hip joint replacement. Clin Orthop Relat Res. 1978;134:135-8.

11. Konyves A, Bannister $\mathrm{G}$. The importance of leg length discrepancy after total hip arthroplasty. J Bone Joint Surg Br. 2005;87(2):155-7.

12. Ranawat CS, Rodriguez J. Functional leg-length inequality following total hip arthroplasty. J Arthroplast. 1997;12(4):359-64.

13. Berend KR, Sporer SM, Sierra RJ, Glassman AH, Morris MJ. Achieving stability and lower-limb length in total hip arthroplasty. JBJS. 2010;92(16):2737-52.

14. Loughenbury F, McWilliams A, Smith M, Pandit H, Stone MH. Leg length inequality after primary total hip arthroplasty. Orthop Trauma. 2018;32(1):2733.

15. Citak M, Kochsiek L, Gehrke T, Haasper C, Suero EM, Mau H. Preliminary results of a 3D-printed acetabular component in the management of extensive defects. Hip Int. 2017;hipint:5000561.

16. Citak M, Kochsiek L, Gehrke T, Haasper C, Mau H. The 3D-printed patientspecific acetabular component in the management of extensive acetabular defect with combined bilateral pelvic discontuinity. In Seminars in Arthroplasty. 2016;27\{4):272-76. WB Saunders.

17. Guggenberger R, Pfirrmann CW, Koch PP, Buck FM. Assessment of lower limb length and alignment by biplanar linear radiography: comparison with supine CT and upright full-length radiography. Am J Roentgenol. 2014; 202(2):W161-W7.

18. Marin E, Fusi S, Pressacco M, Paussa L, Fedrizzi L. Characterization of cellular solids in Ti6Al4V for orthopaedic implant applications: trabecular titanium. J Mech Behav Biomed Mater. 2010;3(5):373-81.
19. Dubousset J, Charpak G, Dorion I, Skalli W, Lavaste F, Deguise J, et al. A new 2D and 3D imaging approach to musculoskeletal physiology and pathology with low-dose radiation and the standing position: the EOS system. Bulletin de l'Academie nationale de medecine. 2005;189(2):287-97 discussion 97300.

20. Schofer MD, Pressel T, Heyse TJ, Schmitt J, Boudriot U. Radiological determination of the anatomic hip Centre from pelvic landmarks. Acta Orthop Belg. 2010;76(4):479.

21. Henckel J, Richards R, Lozhkin K, Harris S, y Baena FR, Barrett A, Cobb J. Very low-dose computed tomography for planning and outcome measurement in knee replacement: the imperial knee protocol. Bone Joint J. 2006;88(11): 1513-8.

22. Dawson J, Fitzpatrick R, Carr A, Murray D. Questionnaire on the perceptions of patients about total hip replacement. J Bone Joint Surg Br. 1996;78(2): 185-90.

23. Kjellberg M, Al-Amiry B, Englund E, Sjödén GO, Sayed-Noor AS. Measurement of leg length discrepancy after total hip arthroplasty. The reliability of a plain radiographic method compared to CT-scanogram. Skelet Radiol. 2012:41(2):187-91.

24. Pathak PK, Gupta RK, Meena HS, Fiske R. Limb length discrepancy after total hip arthroplasty: a systematic review. Int J Res Orthop. 2018;4(5):690.

25. Ng VY, Kean JR, Glassman AH. Limb-length discrepancy after hip arthroplasty. JBJS. 2013;95(15):1426-36.

26. Guichet J-M, Spivak JM, Trouilloud P, Grammont PM. Lower limb-length discrepancy. An epidemiologic study. Clin Orthop Relat Res. 1991;272:23541.

27. Soukka A, Alaranta $H$, Tallroth $K$, Heliövaara M. Leg-length inequality in people of working age. The association between mild inequality and lowback pain is questionable. Spine. 1991;16(4):429-31.

28. Resende RA, Kirkwood RN, Deluzio K, Cabral S, Fonseca ST. Biomechanical strategies implemented to compensate for mild leg length discrepancy during gait. Gait Posture. 2016;46:147-53.

29. Desai AS, Dramis A, Board TN. Leg length discrepancy after total hip arthroplasty: a review of literature. Curr Rev Musculoskelet Med. 2013;6(4): $336-41$.

30. Flecher $\mathrm{X}$, Ollivier M, Argenson J. Lower limb length and offset in total hip arthroplasty. Orthop Traumatol Surg Res. 2016;102(1):S9-S20.

31. Joshi AB, Lee J, Christensen C. Results for a custom acetabular component for acetabular deficiency. J Arthroplast. 2002;17(5):643-8.

\section{Publisher's Note}

Springer Nature remains neutral with regard to jurisdictional claims in published maps and institutional affiliations.

Ready to submit your research? Choose BMC and benefit from:

- fast, convenient online submission

- thorough peer review by experienced researchers in your field

- rapid publication on acceptance

- support for research data, including large and complex data types

- gold Open Access which fosters wider collaboration and increased citations

- maximum visibility for your research: over $100 \mathrm{M}$ website views per year

At BMC, research is always in progress.

Learn more biomedcentral.com/submissions 